\title{
Motor imagery in clinical disorders: importance and implications
}

\author{
Aidan Moran ${ }^{1}$, Jessica Bramham ${ }^{1}$, Christian Collet ${ }^{2}$, Aymeric Guillot ${ }^{2,3}$ and Tadhg Eoghan Maclntyre ${ }^{4}$ \\ 'School of Psychology, University College Dublin, Dublin, Ireland \\ ${ }^{2}$ Centre de Recherche et d'Innovation sur le Sport, Université Claude Bernard Lyon 1, Villeurbanne, France \\ ${ }^{3}$ Institut Universitaire de France, Paris, France \\ ${ }^{4}$ Department of Physical Education and Sport Sciences, University of Limerick, Limerick, Ireland \\ *Correspondence: aidan.moran@ucd.ie
}

Edited by:

David G. Pearson, University of Aberdeen, UK

Reviewed by:

Christopher R. Madan, Boston College, USA

Keywords: motor imagery, mental imagery, post-traumatic stress disorder, personality disorders, social anxiety disorder

One of our most remarkable mental capacities is the ability to use our imagination voluntarily to mimic or simulate sensations, actions, and other experiences. For example, we can "see" things in our mind's eye, "hear" sounds in our mind's ear, and imagine motor experiences like running away from, or perhaps "freezing" in the face of, danger. Since the early 1900s (1), researchers have investigated "mental imagery" or the multimodal cognitive simulation process by which we represent perceptual information in our minds in the absence of sensory input (2).

Although visual imagery has attracted most research attention to date (3), there has been an upsurge of interest in cognitive neuroscience and sport psychology in non-visual simulation processes such as "motor imagery" (MI) - or the mental rehearsal of actions without engaging in the physical movements involved (4). This trend is attributable mainly to the discovery of close parallels between the neurocognitive mechanisms underlying imagination and motor control. Specifically, inspired by Jeannerod's (5-7) simulation theory of action representation, researchers have discovered that MI recruits similar neural pathways and mechanisms to those involved in actual movements. For example, Hétu et al. (8) showed that the neural network of MI includes several cortical regions known to underlie actual motor execution. Building on this apparent functional equivalence between imagined and executed actions, the present article explores the implications of research on MI for increased understanding of three clinical conditions - post-traumatic stress disorder (PTSD), personality disorder, and social anxiety disorder (SAD). Before we begin, however, some background information on imagery processes in psychopathology is required.

Arising from Kosslyn's proposition that mental imagery plays "a special role in representing emotionally charged material" [(9), p. 405; see also Ref. (10)], researchers have examined the role of imagery processes in the onset, maintenance, and treatment of various psychological disorders (11-13). A consistent finding is that negative, vivid, and distressing involuntary ("intrusive") imagery is a "transdiagnostic" feature of depression (14), SAD (15), PTSD (16), and obsessivecompulsive disorder [OCD; (17)]. For example, Weßlau and Steil (14) reported that more than one in three depressed people suffer from involuntary negative mental imagery. Furthermore, people's capacity to use imagery prospectively is significantly impaired in certain clinical disorders. Thus, Morina et al. (18) discovered that depressed patients were less capable of imagining positive future outcomes than were nondepressed controls. Imagery processes also help in the treatment of psychopathology. Indeed, Holmes et al. (19) evaluated the therapeutic value of "imagery rescripting" [where distressing images are modified to change their associated thoughts, feelings, and behavior; (20)] in the treatment of PTSD. Clearly, imagery research represents "a new and important arena" [Pearson et al. (13), p. 3] for clinical psychology.
Despite increased awareness of imagery processes in psychopathology, there is at least one significant gap in research in this field. Specifically, little is known about the role of MI in clinical disorders. Curiously, despite the multimodal nature of imagery (21), clinical researchers have tended to focus mainly on its visual component. Thus, Weßlau and Steil (14) proclaimed that in imagery, although "other sensory components such as smells, sounds, or haptic sensations ... may be present ... the visual aspect is the necessary and sufficient condition" (our italics, p. 274). This proposition may be challenged, however, by evidence that mildly to moderately depressed patients experience proportionately more somatic $(39.6 \%)$ than visual $(27.2 \%)$ imagery (17). More importantly, MI processes may help to elucidate the mechanisms underlying clinical conditions with distinctive motor components. For example, Chen et al. (22) discovered that depressed patients have difficulties in the mental rotation of hand stimuli. These imagery deficits reflect "an underlying slowing down of motor preparation, which may contribute to psychomotor retardation" (p. 341).

Let us now consider three specific disorders in which MI processes are potentially significant - PTSD, personality disorders, and SAD.

\section{POST-TRAUMATIC STRESS DISORDER}

Post-traumatic stress disorder typically involves a threat to an individual's physical integrity [DSM-V; (23)]. This threat may prompt movement execution either 
through resistance to attack (fight) or through intended escape (flight) (24). Accordingly, it seems plausible that reexperiencing a traumatic event in the form of "flashbacks" will involve MI. Corroborating this hypothesis, research shows that flashbacks are associated with increases in various types of motor behavior (25). More recently, neuroimaging paradigms in which individuals with PTSD imagine their traumatic experience or simulate flashbacks have shown increased cerebral blood flow to the motor cortex including the precentral gyrus and supplementary motor area $(26,27)$. These findings shed light on the neurocognitive mechanisms underlying PTSD disorders because they confirm the involvement of motor cortex in the simulated re-experiencing of traumatic events.

Another link between PTSD and MI processes has emerged from recent studies of the "freeze" response or tonic immobility. Briefly, tonic immobility is an involuntary, reflexive state, characterized by apparent physical paralysis, muscular rigidity, and inability to vocalize $(28,29)$. For animals, it may be a last line of defense because it reduces the likelihood that predators will continue to attack them (30). The freeze response is more complex in humans, however, as it may be triggered by symbolic events such as the perception that a situation is inescapable (31). Interestingly, although "freezing" was first noted as a characteristic of sexual assault (32) - with up to $37-52 \%$ of such assault survivors reporting tonic immobility - it has also been identified among victims of other traumas including physical assault and natural disasters (33). Accordingly, tonic immobility has been proposed as a core sign of trauma in PTSD (34). Unfortunately, peri-traumatic tonic immobility has been shown to predict a poor response to pharmacological treatment $(35,36)$ which suggests that psychological processes may be especially significant in this form of PTSD. Recently, Bovin et al. (37) discovered that guilt (i.e., negative evaluation of an action or inaction) mediated the association between tonic immobility and PTSD symptom severity. These authors speculated that guilt may be a mechanism through which individuals develop PTSD following tonic immobility. The argument here is that during the tonic immobility experienced in the trauma situation, victims may feel guilty about their lack of action - which renders them especially vulnerable to developing PTSD. As tonic immobilization is a key risk factor for PTSD, interventions that are targeted to remediate the impact of the freeze response could provide a fruitful strategy for the reduction or prevention of PTSD symptoms (36). Therefore, we propose that rescripting based on MI ("remobilizing") could prove valuable as an intervention technique for PTSD (38).

Recent studies show that tonic immobility during childhood sexual abuse is associated with the onset of subsequent PTSD symptomatology in adulthood (39). The freeze response, or "learned helplessness," is especially likely in cases of trauma experienced by infants or young children who are physically unable to escape (40). Further insights into MI processes in PTSD spring from research on the differences between patients' memories of traumatic events and those of non-traumatic events. Thus, van der Kolk and Fisler (41) suggested that trauma is initially represented using somatosensory information - with traumatic experiences being remembered as bodily sensations. Consistent with this proposal, Malmo and Suzuki Laidlaw (42) found that people who had no memory of childhood sexual abuse prior to therapy were "more kinesthetic than visual" in their orientation to the world. Remarkably, during therapy, the "no memory of trauma" participants became aware of their traumatic memories, and were consistently able to report kinesthetic memory details such as their bodily position in relation to that of the perpetrator (42).

\section{PERSONALITY DISORDERS}

The development of personality disorders, particularly borderline personality disorder, has been strongly associated with early trauma and neglect (43-45). Interestingly, certain kinds of imagery rescripting such as re-imagining adverse early childhood events from an adult perspective have been used to treat personality disorders (46). Imagery rescripting was first used by Arntz and Weertman (47) with the primary objective of revising the perceived meaning of events. For example, an image of a childhood memory might be rescripted constructively by imagining an adult entering the scene and intervening in a positive way (e.g., comforting the child concerned). Typically, the rescripting session with the therapist is recorded and the patient then listens to the recording and practices the exercise again at home, where possible using imagery. Later, patients themselves are required to rescript the adverse event. Although imagery rescripting in a promising therapeutic strategy, its efficacy is mediated by many psychological variables. For example, consider the role of "imagery perspective" or the virtual vantage pointof-view adopted by the person imagining [e.g., first-person versus third-person perspective; (48)]. To illustrate, one can "feel" oneself performing an action with one's body (first-person perspective) or one can "see" oneself or someone else performing that action (third-person perspective). Imagery perspective is important in the treatment of trauma because McIsaac and Eich (49) found that traumatic images retrieved from a third-person perspective were experienced as less emotional than those retrieved from a first-person perspective. Unfortunately, few studies have explored the relative efficacy of different perspectives [which may involve different levels of embodiment (48)] in rescripting imagery interventions.

\section{SOCIAL ANXIETY DISORDER}

Social anxiety disorder is a highly prevalent and disabling condition that involves fear and avoidance of interpersonal interactions, particularly those that involve potential for social evaluation (50). This disorder is typically characterized by vivid visual imagery, particularly that generated from a third-person perspective (51). According to cognitive models of social anxiety [e.g., by Clark and Wells (52)], people with SAD habitually generate negative images from thoughts, feelings, and bodily sensations to create impressions of how they appear to others from a third-person ("observer") perspective. Intriguingly, Spurr and Stopa discovered that imagery experienced from a third-person perspective is associated with increased negative self-evaluation by comparison with that occurring from a first-person perspective (53).

One strategy for treating social anxiety involves helping patients to restructure their imagery experiences (54). Thus, Wild et al. (55) developed an imagery-based 
technique to help people to modify traumatic memories. This technique is effective as a brief treatment for social phobia (56). Its use of imagery rescripting is similar to that pioneered by Arntz and Weertman (47) and involves closing one's eyes, describing recurring images in social situations, and then imagining that the current self is present at the scene and hence, intervening appropriately. This latter imagery clearly has a motor component as it involves re-imagining actions or movements. Accordingly, MI may be helpful for the treatment of SAD because it can orient patients away from the critical self-focused perspective, thereby reducing "egocentric awareness" (57). By contrast, self-focused attention may impair people's capacity for perspective-taking, thereby maintaining social anxiety (58).

\section{CONCLUSION AND FUTURE DIRECTIONS}

In this article, we have presented two main arguments concerning imagery processes in psychopathology. Firstly, we postulated that research on MI processes offers intriguing insights into the neurocognitive mechanisms underlying, and psychological treatment of, certain clinical disorders (specifically, PTSD, personality disorders, and SAD). In addition, we proposed that clinical researchers have much to learn from an emerging theoretical theme in cognitive neuroscience - namely, the idea that the brain is a dynamic predictive system (59) which uses simulation as a mechanism for integrating the psychological processes of imagination, perception, and action. More immediately, however, several priorities may be identified for future research on MI in clinical disorders. Firstly, greater theoretical and linguistic precision is required in the delineation of different imagery modalities and experiences. For example, some researchers [e.g., Arntz (46)] use the generic term "imagery" to refer to quite different simulation phenomena such as imagining bodily movements and visualizing scenes. Secondly, in assessing problems such as psychomotor retardation, clinical researchers can benefit from the systematic use of objective measures of MI (60) - especially recently developed psychometric tests (61). Finally, on the basis that dynamic mental practice (i.e., imagining a skill while making associated physical movements) can improve skilled performance through enhanced mental representation (62), it seems plausible that dynamic imagery rescripting could enrich therapeutic interventions for patients suffering from certain disorders (e.g., PTSD).

\section{REFERENCES}

1. Betts GH. The Distribution and Functions of Mental Imagery. (Vol. 26). New York: Teachers' College Columbia University Contributions to Education (1909). p. 1-99.

2. Munzert J, Lorey J, Zentgraf J. Cognitive motor processes: the role of motor imagery in the study of motor representations. Brain Res Rev (2009) 60:306-26. doi:10.1016/j.brainresrev.2008.12.024

3. Reisberg D. Mental images. In: Reisberg D, editor. The Oxford Handbook of Cognitive Psychology. Oxford: Oxford University Press (2013). p. 374-87.

4. Moran A, Guillot A, MacIntyre T, Collet C. Re-imagining motor imagery: building bridges between cognitive neuroscience and sport psychology. Br J Psychol (2012) 103:224-47. doi:10.1111/ j.2044-8295.2011.02068.x

5. Jeannerod $M$. The representing brain: neural correlates of motor intention and imagery. Behav Brain Sci (1994) 17:187-202. doi:10.1017/ S0140525X00034026

6. Jeannerod M. Neural simulation of action: a unifying mechanism for motor cognition. Neuroimage (2001) 14:S103-9. doi:10.1006/nimg.2001.0832

7. Jeannerod M. Motor Cognition. New York, NY: Oxford University Press (2006).

8. Hétu S, Grégoire M, Saimpont A, Coll M-P, Eugène F, Michon P-E, et al. The neural network of motor imagery: an ALE meta-analysis. Neurosci Biobehav Rev (2013) 37:930-49. doi:10.1016/j.neubiorev. 2013.03.017

9. Kosslyn SM. Image and Bain: The Resolution of the Imagery Debate. Cambridge, MA: MIT Press (1994).

10. Lang PJ. A bio-informational theory of emotional imagery. Psychophysiol (1979) 16:495-512. doi:10. 1111/j.1469-8986.1979.tb01511.x

11. Brewin CR, Gregory JD, Lipton M, Burgess N. Intrusive images in psychological disorders: characteristics, neural mechanisms, and treatment implications. Psychol Rev (2010) 117(1):210-32. doi:10.1037/a0018113

12. Holmes EA, Mathews A. Mental imagery in emotion and emotional disorders. Clin Psychol Rev (2010) 30:349-62. doi:10.1016/j.cpr.2010.01.001

13. Pearson DG, Deeprose C, Wallace-Hadrill SMA, Burnett Heyes S, Holmes EA. Assessing mental imagery in clinical psychology: a review of imagery measures and a guiding framework. Clin Psychol $\operatorname{Rev}(2013)$ 33:1-23. doi:10.1016/j.cpr.2012.09.001

14. Weßlau C, Steil R. Visual mental imagery in psychopathology - implications for the maintenance and treatment of depression. Clin Psychol Rev (2014) 34(4):273-81. doi:10.1016/j.cpr.2014. 03.001

15. Hirsch CR, Clark DM, Mathews A. Imagery and interpretations in social phobia: support for the combined cognitive biases hypothesis. Behav Ther (2006) 37(3):223-36. doi:10.1016/j. beth.2006.02.001
16. Holmes EA, Grey N, Young KAD. Intrusive images and "hotspots" of trauma memories in posttraumatic stress disorder. J Behav Ther Exp Psychiatry (2005) 36(1):3-17. doi:10.1016/j.jbtep.2004. 11.002

17. Klein JP, Moritz S. On the relevance of mental imagery beyond stress-related psychiatric disorders. Front Psychiatry (2014) 5:77. doi:10.3389/ fpsyt.2014.00077

18. Morina N, Deeprose C, Pusowski C, Schmid $\mathrm{M}$, Holmes EA. Prospective mental imagery in patients with major depressive disorder or anxiety disorders. J Anxiety Disord (2011) 25:1032-7. doi:10.1016/j.janxdis.2011.06.012

19. Holmes EA, Arntz A, Smucker MR. Imagery rescripting in cognitive behaviour therapy: images, treatment techniques and outcomes. J Behav Ther Exp Psychiatry (2007) 38(4):297-305. doi:10.1016/ j.jbtep.2007.10.007

20. Long ME, Quevillion R. Imagery rescripting in the treatment of posttraumatic stress disorder. J Cogn Psychother (2009) 23(1):67-76. doi:10.1891/08898391.23.1.67

21. Moulton ST, Kosslyn SM. Imagining predictions: mental imagery as mental emulation. Philos Trans $R$ Soc Lond B Biol Sci (2009) 364:1273-80. doi:10. 1098/rstb.2008.0314

22. Chen J, Yang LQ, Zhang ZJ, Ma WT, Wu XQ, Zhang $\mathrm{XR}$, et al. The association between the disruption of motor imagery and the number of depressive episodes of major depression. J Affect Disord (2013) 150(2):337-43. doi:10.1016/j.jad.2013. 04.015

23. American Psychiatric Association. Diagnostic and Statistical Manual of Mental Disorders: DSM-5. 5 ed. Arlington, VA: American Psychiatric Association (2013).

24. Baldwin DV. Primitive mechanisms of trauma response: an evolutionary perspective on traumarelated disorders. Neurosci Biobehav Rev (2013) 37(8):1549-66. doi:10.1016/j.neubiorev.2013.06. 004

25. Hellawell SJ, Brewin CR. A comparison of flashbacks and ordinary autobiographical memories of trauma: cognitive resources and behavioural observations. Behav Res Ther (2002) 40(10):1143-56. doi:10.1016/S0005-7967(01) 00080-8

26. Whalley MG, Kroes MC, Huntley Z, Rugg MD, Davis SW, Brewin CR. An fMRI investigation of posttraumatic flashbacks. Brain $\operatorname{Cogn}$ (2013) 81(1):151-9. doi:10.1016/j.bandc.2012.10.002

27. Barkay G, Freedman N, Lester H, Louzoun Y, Sapoznikov D, Luckenbaugh D, et al. Brain activation and heart rate during script-driven traumatic imagery in PTSD: preliminary findings. Psychiatry Res (2012) 204(2-3):155-60. doi:10.1016/ j.pscychresns.2012.08.007

28. Marx BP, Forsyth JP, Gallup GG, Lexington JM. Fusé $\mathrm{T}$, Tonic immobility as an evolved predator defence: implications for sexual assault survivors. Clin Psychol Sci Practice (2008) 15(1):74-90. doi: 10.1111/j.1468-2850.2008.00112.x

29. Hagenaars MA, Oitzl M, Roelofs K. Updating freeze: aligning animal and human research. $\mathrm{Neu}$ rosci Biobehav Rev (2014) 47:165-76. doi:10.1016/ j.neubiorev.2014.07.021

30. Monassi CR, Leite-Panissi CR, Menescal-deOliveira L. Ventrolateral periaqueductal gray 
matter and the control of tonic immobility. Brain Res Bull (1999) 50(3):201-8. doi:10.1016/S03619230(99)00192-6

31. Bracha HS. Freeze, flight, fight, fright, faint: adaptationist perspectives on the acute stress response spectrum. CNS Spectr (2004) 9(9):679-85.

32. Russell DEH. The Politics of Rape: The Victim's Perspective. New York, NY: Stein and Day (1974).

33. Abrams MP, Carleton RN, Taylor S, Asmundson GJ. Human tonic immobility: measurement and correlates. Depress Anxiety (2009) 26(6):550-6. doi:10.1002/da.20462

34. Rocha-Rego V, Fiszman A, Portugal LC, Garcia Pereira M, de Oliveira L, Mendlowicz MV, et al. Is tonic immobility the core sign among conventional peritraumatic signs and symptoms listed for PTSD? J Affect Disord (2009) 115(1-2):269-73. doi:10.1016/j.jad.2008.09.005

35. Fiszman A, Mendlowicz MV, Marques-Portella C, Volchan E, Coutinho ES, Souza WF, et al. Peritraumatic tonic immobility predicts a poor response to pharmacological treatment in victims of urban violence with PTSD. J Affect Disord (2008) 107(13):193-7. doi:10.1016/j.jad.2007.07.015

36. Lima AA, Fiszman A, Marques-Portella C, Mendlowicz MV, Coutinho ES, Maia DC, et al. The impact of tonic immobility reaction on the prognosis of posttraumatic stress disorder. J Psychiatr Res (2010) 44(4):224-8. doi:10.1016/j.jpsychires. 2009.08.005

37. Bovin MJ, Dodson TS, Smith BN, Gregor K, Marx BP, Pineles SL. Does guilt mediate the association between tonic immobility and posttraumatic stress disorder symptoms in female trauma survivors? J Trauma Stress (2014) 27(6):721-4. doi: $10.1002 /$ jts. 21963

38. Oktedalen T, Hoffart A, Langkaas TF. Traumarelated shame and guilt as time-varying predictors of posttraumatic stress disorder symptoms during imagery exposure and imagery rescripting-a randomized controlled trial. Psychother Res (2014) 23:1-15. doi:10.1080/10503307.2014.917217

39. Humphreys KL, Sauder CL, Martin EK, Marx BP. Tonic immobility in childhood sexual abuse survivors and its relationship to posttraumatic stress symptomatology. J Interpers Violence (2010) 25(2):358-73. doi:10.1177/0886260509334412

40. Lyons-Ruth K, Dutra L, Schuder MR, Bianchi I. From infant attachment disorganization to adult dissociation: relational adaptations or traumatic experiences? Psychiatr Clin North Am (2006) 29(1):63-86. doi:10.1016/j.psc.2005.10.011

41. van der Kolk BA, Fisler R. Dissociation and the fragmentary nature of traumatic memories: overview and exploratory study. J Trauma Stress (1995) 8(4):505-25. doi:10.1007/BF02102887

42. Malmo C, Suzuki Laidlaw TS. Symptoms of trauma and traumatic memory retrieval in adult survivors of childhood sexual abuse. J Trauma
Dissociation (2010) 11(1):22-43. doi:10.1080/ 15299730903318467

43. Patrick M, Hobson RP, Castle P, Howard R, Maughan B. Personality disorder and the mental representation of early social experience. Dev Psychopathol (1994) 6:375-88. doi:10.1017/ S0954579400004648

44. Bandelow B, Krause J, Wedekind D, Broocks A, Hajak G, Rüther E. Early traumatic life events, parental attitudes, family history, and birth risk factors in patients with borderline personality disorder and healthy controls. Psychiatry Res (2005) 134(2):169-79. doi:10.1016/j.psychres. 2003.07.008

45. Johnson JG, Smailes EM, Cohen P, Brown J, Bernstein DP. Associations between four types of childhood neglect and personality disorder symptoms during adolescence and early adulthood: findings of a community-based longitudinal study. J Pers Disord (2000) 14(2):171-87. doi:10.1521/ pedi.2000.14.2.171

46. Arntz A. Imagery rescripting for personality disorders. Cogn Behav Pract (2011) 18:466-81. doi:10. 1016/j.cbpra.2011.04.006

47. Arntz A, Weertman A. Treatment of childhood memories: theory and practice. Behav Res Ther (1999) 37(8):715-40. doi:10.1016/S00057967(98)00173-9

48. Madan CR, Singhal A. Motor imagery and higherlevel cognition: four hurdles before research can sprint forward. Cogn Process (2012) 13:211-29. doi:10.1007/s10339-012-0438-z

49. McIsaac HK, Eich E. Vantage point in traumatic memory. Psychol Sci (2004) 15(4):248-54. doi:10. 1111/j.0956-7976.2004.00660.x

50. Miskovic V, Schmidt LA. Social fearfulness in the human brain. Neurosci Biobehav Rev (2012) 36(1):459-78. doi:10.1016/j.neubiorev. 2011.08.002

51. Hackmann A, Surawy C, Clark DM. Seeing yourself through others' eyes: a study of spontaneously occurring images in social phobia. Behav Cogn Psychother (1998) 26:3-12. doi:10.1017/ S1352465898000022

52. Clark DM, Wells A. A cognitive model of socia phobia. In: Heimberg R, Liebowitz M, Hope DA, Schneier FR, editors. Social Phobia: Diagnosis, Assessment and Treatment. New York, NY: Guildford Press (1995). p. 69-93.

53. Spurr JM, Stopa L. The observer perspective: effects on social anxiety and performance. Behav Res Ther (2003) 41(9):1009-28. doi:10.1016/S00057967(02)00177-8

54. Harvey AG, Clark DM, Ehlers A, Rapee RM. Social anxiety and self-impression: cognitive preparation enhances the beneficial effects of video feedback following a stressful social task. Behav Res Ther (2000) 38(12):1183-92. doi:10.1016/S00057967(99)00148-5
55. Wild J, Hackmann A, Clark DM. Rescripting early memories linked to negative images in social phobia: a pilot study. Behav Ther (2008) 39(1):47-56. doi:10.1016/j.beth.2007.04.003

56. Lee SW, Kwon JH. The efficacy of imagery rescripting (IR) for social phobia: a randomized controlled trial. J Behav Ther Exp Psychiatry (2013) 44(4):351-60. doi:10.1016/j.jbtep.2013.03.001

57. Kozhevnikov M, Hegarty M. A dissociation between object manipulation spatial ability and spatial orientation ability. Mem Cognit (2001) 29(5):745-56. doi:10.3758/BF03200477

58. Rapee RM, Heimberg RG. A cognitive-behavioral model of anxiety in social phobia. Behav Res Ther (1997) 35(8):741-56. doi:10.1016/S0005-7967(97) 00022-3

59. Pezzullo G, Candido M, Dindo H, Barca L. Action simulation in the human brain: twelve questions. New Ideas Psychol (2013) 31:270-90. doi:10.1093/ bja/aet326

60. Collet C, Guillot A, Lebon F, MacIntyre T, Moran A. Measuring motor imagery: combining psychometric, qualitative, chronometric, and psychophysiological techniques. Exerc Sport Sci Rev (2011) 39:85-92. doi:10.1097/JES.0b013e31820ac5e0

61. Madan CR, Singhal A. Introducing TAMI: an objective test of ability in movement imagery. JMot Behav (2013) 45:153-66. doi:10.1080/00222895. 2013.763764

62. Guillot A, Moschberger K, Collet C. Coupling movement with imagery as a new perspective for motor imagery practice. Behav Brain Funct (2013) 9:8. doi:10.1186/1744-9081-9-8

Conflict of Interest Statement: The authors declare that the research was conducted in the absence of any commercial or financial relationships that could be construed as a potential conflict of interest.

Received: 08 December 2014; accepted: 04 February 2015; published online: 18 February 2015.

Citation: Moran A, Bramham J, Collet C, Guillot A and MacIntyre TE (2015) Motor imagery in clinical disorders: importance and implications. Front. Psychiatry 6:23. doi: 10.3389/fpsyt.2015.00023

This article was submitted to Affective Disorders and Psychosomatic Research, a section of the journal Frontiers in Psychiatry.

Copyright (c) 2015 Moran, Bramham, Collet, Guillot and MacIntyre. This is an open-access article distributed under the terms of the Creative Commons Attribution License (CC BY). The use, distribution or reproduction in other forums is permitted, provided the original author(s) or licensor are credited and that the original publication in this journal is cited, in accordance with accepted academic practice. No use, distribution or reproduction is permitted which does not comply with these terms. 